\title{
Post-transcriptional regulation of MRE11 expression in muscle- invasive bladder tumours
}

\author{
Rebecca M. Martin ${ }^{1}$, Martin Kerr ${ }^{1}$, Mark T.W. Teo ${ }^{2}$, Sarah J. Jevons ${ }^{1}$, Marianne \\ Koritzinsky $^{3}$, Bradly G. Wouters ${ }^{3}$, Selina Bhattarai ${ }^{4}$, Anne E. Kiltie ${ }^{1}$ \\ ${ }^{1}$ Gray Institute for Radiation Oncology and Biology, Department of Oncology, University of Oxford, Oxford, UK \\ ${ }^{2}$ Section of Epidemiology and Biostatistics, Leeds Institute of Cancer and Pathology, Leeds, UK \\ 3 Princess Margaret Cancer Centre, University Health Network, Toronto, Canada and Department of Radiation Oncology, \\ University of Toronto, Toronto, Canada \\ ${ }^{4}$ Department of Histopathology and Molecular Pathology, St James's University Hospital, Leeds, UK \\ Correspondence to: Anne E Kiltie, email: anne.kiltie@oncology.ox.ac.uk \\ Key words: MRE1 1, bladder cancer, post-transcriptional regulation, microRNA, miR-153, protein stability \\ Received: November 25, $2013 \quad$ Accepted: January 14, 2014 \\ Published: January 14, 2014
}

This is an open-access article distributed under the terms of the Creative Commons Attribution License, which permits unrestricted use, distribution, and reproduction in any medium, provided the original author and source are credited.

\section{ABSTRACT:}

Predictive assays are needed to help optimise treatment in muscle-invasive bladder cancer, where patients can be treated by either cystectomy or radical radiotherapy. Our finding that low tumour MRE11 expression is predictive of poor response to radiotherapy but not cystectomy was recently independently validated. Here we investigated further the mechanism underlying low MRE11 expression seen in poorly-responding patients. MRE11 RNA and protein levels were measured in 88 bladder tumour patient samples, by real-time PCR and immunohistochemistry respectively, and a panel of eight bladder cancer cell lines was screened for MRE11, RAD50 and NBS1 mRNA and protein expression. There was no correlation between bladder tumour MRE11 protein and RNA scores (Spearman's rho $0.064, p=0.65$ ), suggesting MRE11 is controlled post-transcriptionally, a pattern confirmed in eight bladder cancer cell lines. In contrast, NBS1 and RAD50 mRNA and protein levels were correlated $(p=0.01$ and $p=0.03$, respectively), suggesting primary regulation at the level of transcription. MRE11 protein levels were correlated with NBS1 and RAD50 mRNA and protein levels, implicating MRN complex formation as an important determinant of MRE11 expression, driven by RAD50 and NBS1 expression. Our findings of the post-transcriptional nature of the control of MRE11 imply that any predictive assays used in patients need to be performed at the protein level rather than the mRNA level.

\section{INTRODUCTION}

Muscle invasive bladder cancer can be treated by surgical removal of the bladder (cystectomy) or radical radiotherapy, with similar cure rates [1]. However, it is not currently possible to choose the better option for an individual patient, based on known clinicopathological parameters. There is therefore an urgent need to develop predictive biomarkers in this disease. In two cohorts of radiotherapy patients, we found that patients whose tumours expressed low levels of the DNA damage signalling protein, MRE11, as measured by immunohistochemistry (IHC), had a significantly worse survival rate following radiotherapy than those expressing high levels of MRE11 (43\% versus 70\% 3-year cause-specific survival) [2]. Low MRE11 expression was predictive of poor response to radiotherapy, rather than being a prognostic marker in bladder cancer, as expression was not correlated with outcome in our surgical cohort. More recently, Laurberg et al [3] confirmed our MRE11 IHC findings in a Danish surgical and German chemoradiotherapy cohort. We observed lower MRE11 expression in tumour cells than normal urothelium [2], as seen previously in breast tumours [4, 5]; low MRE11 was associated with poorer radiotherapy outcomes in breast 
cancer [5].

MRE11 is a component of the MRN complex with RAD50 and NBS1, and stability of the three MRN proteins is linked, with MRE11 mutations which destabilise the MRN complex being associated with reduced RAD50 and NBS1 protein levels [6]. Re-expression of MRE11 in such mutant cells results in increased levels of MRE11, RAD50 and NBS1 proteins $[6,7]$. The MRN complex contributes to the DNA damage response, detecting DNA breaks and signalling to checkpoint kinases [8]. The crystal structure of the human MRE11 core has recently been determined [9]. Through its exonuclease activity, MRE11, along with CtIP, resects DNA ends during homologous recombination [10] and promotes microhomologymediated end-joining over conventional non-homologous end-joining [11]. MRE11 is also required for telomeric maintenance [12]. Cells defective in MRE11 expression are unusually radiosensitive [6], and treatment with the MRE11 inhibitor Mirin results in inhibition of radiationinduced phosphorylation of ATM [13, 14]. Therefore our validated IHC result was intriguing, as it was anticipated that reduced expression of proteins involved in DNA repair such as MRE11 would increase patient survival after radiotherapy, through greater tumour radiosensitivity from reduced repair of DNA double-strand breaks.

The aims of the present study were to further our understanding of the mechanisms underlying the low tumour MRE11 protein expression seen in poorly responding bladder cancer patients, as potentially this could be exploited clinically, and to determine the level of control, relative to transcription. We wished to test the hypotheses that underlying control mechanisms determine MRE11 protein expression levels, and that expression levels of NBS1 and RAD50 might also influence MRE11 expression.

\section{RESULTS}

\section{MRE11 protein expression is controlled at the post-transcriptional level and correlates with expression of RAD50 and NBS1}

To determine the range of MRE11 protein expression levels in radiotherapy patients' tumour samples and to determine whether control of expression occurs pre- or post-transcriptionally, FFPE patient tumour sections were stained by IHC for MRE11 and $0.6 \mathrm{~mm}$ cores taken from a homogeneous tumour area for RNA extraction. RNA of sufficient quantity and quality was extracted from 83 of 88 tumours. Fourteen tumours were excluded as the combined $\mathrm{Ct}$ value for both endogenous controls was greater than two standard deviations from

a
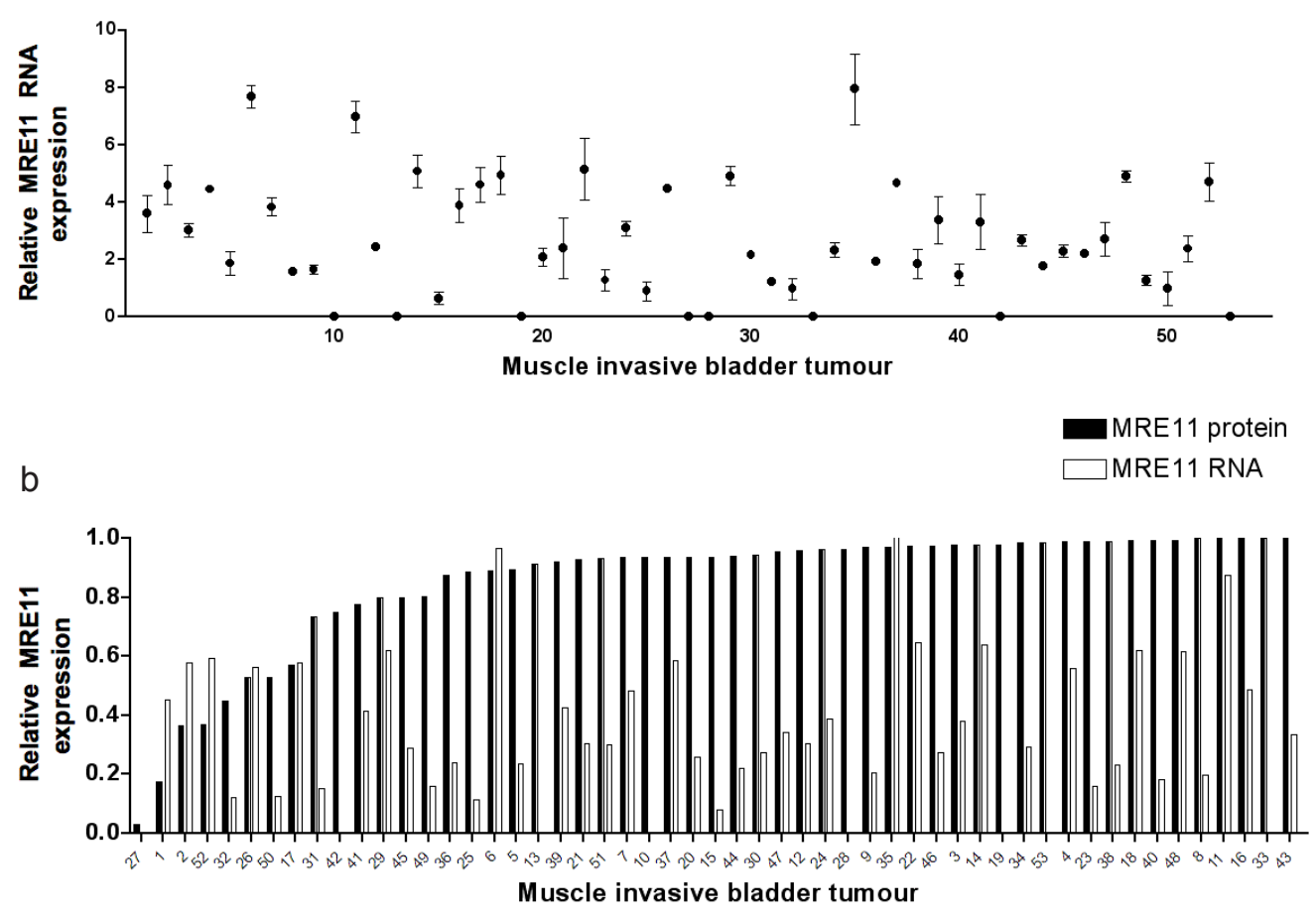

Figure 1: Bladder tumour MRE11 RNA and protein expression levels. a) QPCR of RNA from FFPE bladder tumours (n=53), using SDHA and ATPB as endogenous controls. Data points represent values relative to the lowest value above zero. Error bars represent the standard error of the mean (SEM) from technical duplicates. b) Tumour MRE11 QPCR and IHC scores expressed relative to the highest value for each. 
the mean; a further 16 tumours were excluded due to inconsistencies between technical replicates. Fifty-three tumours yielded high quality data that were normalised against endogenous controls and set relative to the highest value (Figure 1). MRE11 RNA expression was below detectable levels in eight tumours, but PCR failure was ruled out as other experiments on the same plate were successful and the result was repeated on at least one other occasion. This result was therefore taken to represent extremely low MRE11 RNA expression. IHC scores were also plotted relative to the highest value and compared to QPCR results. Spearman Rank Correlation revealed no correlation between protein and RNA scores (Spearman's rho $(\rho)$ 0.064, $p=0.65$ ), suggesting that differences in MRE11 protein expression occur as a result of posttranscriptional events.

The same Taqman assay was used to detect MRE11 RNA expression in a panel of bladder cancer cell lines and a similar discordance was seen between RNA expression and protein expression, by western blotting (Figure 2, $\mathrm{p}=0.42$, and Supplementary Figure 1). However, RNA and protein expression were correlated for both NBS1 $(\mathrm{p}=0.01)$ and RAD50 ( $\mathrm{p}=0.03)$, using SYBR green. While there was no correlation between MRN complex members' mRNA expression levels, western blot quantification revealed correlations between MRE11, RAD50 and NBS1 protein expression (all $\mathrm{p}=0.002$ or less), and MRE11 protein levels also correlated with both RAD50 and NBS1 mRNA levels (Figure 2b).

\section{microRNA-153 expression is associated with reduced MRE11 protein expression}

In our clinical samples, MRE11 appeared to be controlled at the post-transcriptional level. Therefore we decided to study various factors which could be involved, namely RNA stability, protein translation initiation and protein stability. Binding of microRNAs to the 3'UTRs of mRNAs, a major post-transcriptional gene regulatory mechanism, inhibits translation of messenger RNA, by targeting it for degradation or inhibiting translation initiation.

The online database Targetscan identified miR9 and miR-153 as having a high probability of binding to MRE11's 3'UTR (Fig 3a), and these miRNAs have higher expression in urothelial tumours than normal tissues (J Catto, personal communication, 30 Oct 2013). Therefore luciferase assays were performed in which either pre-miR-9 or pre-miR-153 was co-transfected with an MRE11 3'UTR-luciferase construct into 5637 bladder cancer cells (Figure 3b and Supplementary figure 2), chosen for transfection efficiency of both plasmid DNA constructs and small RNAs. miR-9 had a small, borderline significant effect on luciferase activity $(p=0.06)$, whereas transfection of miR-153 markedly reduced luciferase activity $(p=0.002)$. This functional assay suggested that miR-153 can bind the MRE11 3'UTR and inhibit gene expression, whereas miR-9 has only a relatively weak effect.

Expression of miR-9 and miR-153 was determined
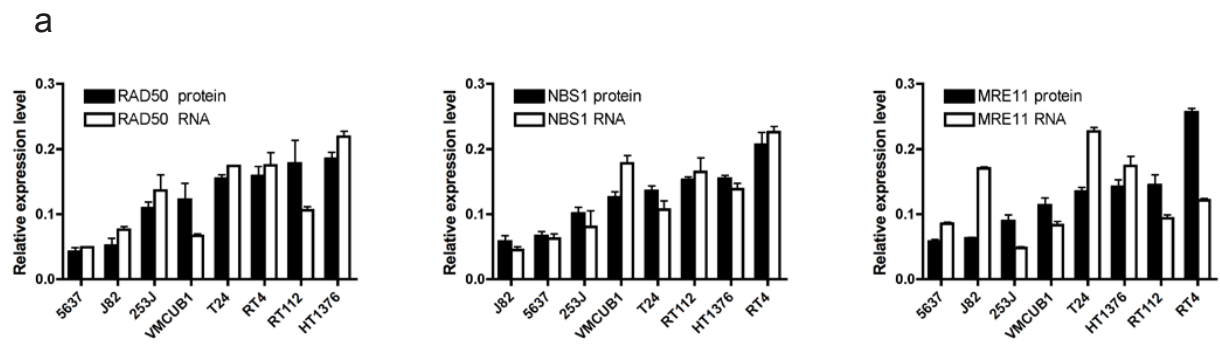

b

\begin{tabular}{|c|c|c|c|c|c|c|}
\hline \multicolumn{7}{|l|}{ MRE11 RNA } \\
\hline RAD50 RNA & $\begin{array}{l}0.548 \\
0.160\end{array}$ & & & & & \\
\hline NBS1 RNA & $\begin{array}{l}-0.48 \\
0.911\end{array}$ & $\begin{array}{l}0.381 \\
0.352\end{array}$ & & & & \\
\hline MRE11 Protein & $\begin{array}{l}0.333 \\
0.420\end{array}$ & $\begin{array}{l}0.714 \\
0.047 *\end{array}$ & $\begin{array}{l}0.833 \\
0.010^{*}\end{array}$ & & & \\
\hline RAD50 Protein & $\begin{array}{l}0.429 \\
0.289\end{array}$ & $\begin{array}{l}0.762 \\
0.028^{*}\end{array}$ & $\begin{array}{c}0.69 \\
0.058\end{array}$ & $\begin{array}{l}0.905 \\
0.002 *\end{array}$ & & \\
\hline NBS1 Protein & $\begin{array}{l}0.333 \\
0.420 \\
\end{array}$ & $\begin{array}{l}0.762 \\
0.028^{*}\end{array}$ & $\begin{array}{l}0.833 \\
0.010^{*}\end{array}$ & $\begin{array}{c}0.952 \\
<0.001^{*}\end{array}$ & $\begin{array}{c}0.905 \\
0.002^{*}\end{array}$ & \\
\hline & MRE11 RNA & RAD50 RNA & NBS1 RNA & MRE11 Prote & RAD50 Proteir & NBS1 Protein \\
\hline
\end{tabular}

Figure 2: Expression of MRE11, RAD50 and NBS1 RNA and protein in eight bladder cancer cell lines. a) comparison of QPCR and western blotting data for RAD50 ( $\rho=0.762, p=0.03)$, NBS1 $(\rho=0.833, p=0.01)$ and MRE11 (Spearman's rho 0.333, p=0.42). Error bars: SEM of three experiments. b) Spearman correlation coefficients (top) with p values (bottom) for each comparison. 
by QPCR in tumours using total RNA extracted from FFPE tissues from additional tumour cores, mentioned previously. miRNAs, being much smaller than mRNA

a
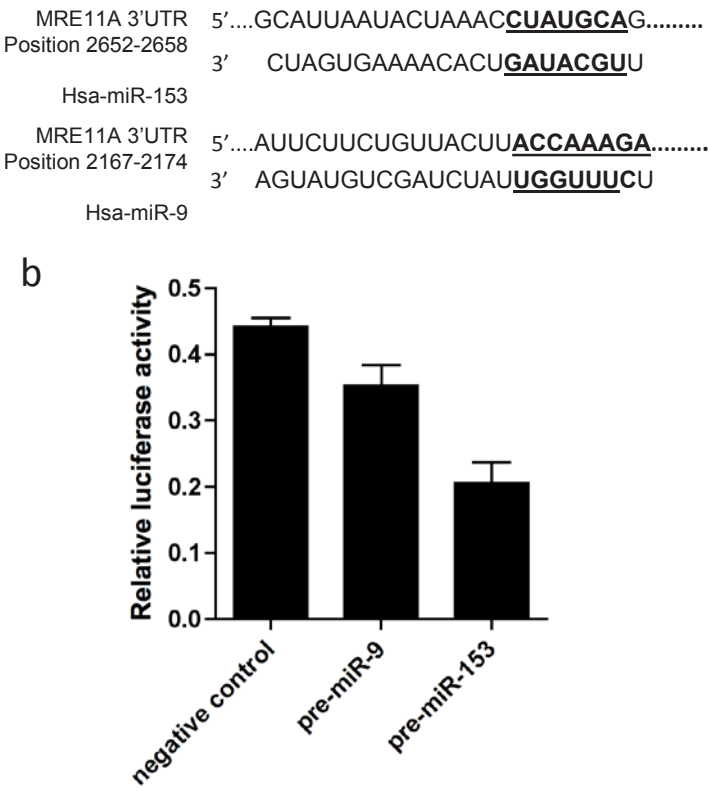

C

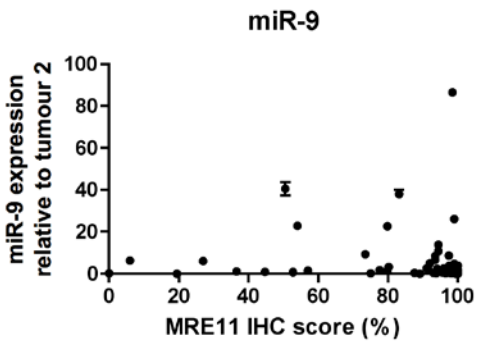

d

miR-153

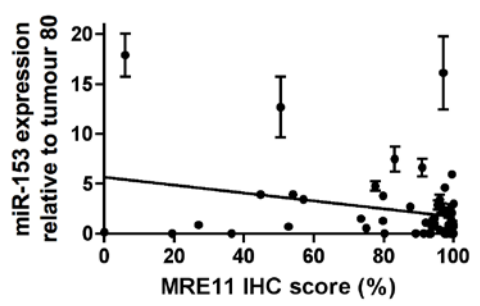

Figure 3: Effects of microRNA-9 and microRNA-153 on MRE11 protein expression in bladder cancer. a) binding sites of miRNAs to MRE11 3'UTR; b) transfection of 5637 cells with a construct containing the MRE11 3'UTR cloned downstream of firefly luciferase, pre-miR-9, pre-miR-153 or negative control, and renilla luciferase internal control; c) correlation between microRNA-9 $(\mathrm{n}=56)$, and d) microRNA-153 expression $(n=54)$ with bladder tumour MRE11 IHC protein expression. Error bars: SEM of technical duplicates. can be reliably measured in FFPE material [15]. Sixtytwo tumours yielded RNA of sufficient quality and quantity for analysis. Six tumours were excluded as combined levels of endogenous controls RNU44 and RNU48 were over two standard deviations from the mean, leaving 56 tumours with high quality data available. Two tumours were excluded from the miR-153 study due to inconsistencies in technical replicates or QPCR failure. In general, expression of both microRNAs was low, with higher expression in relatively few tumours (Figure 3 c-d). There was no correlation between miR-9 expression and MRE11 IHC score ( $\mathrm{p}=0.14)$, but miR-153 expression was inversely correlated with IHC expression $(\rho-0.403$, $\mathrm{p}=0.003)$, consistent with our in vitro data.

\section{Translation initiation does not affect MRE11 expression}

Although we observed a relationship between miR153 and protein levels for MRE11, no correlation was observed with mRNA expression (data not shown). We hypothesized that miR-153 could influence protein levels by inhibiting translation initiation of MRE11 in bladder
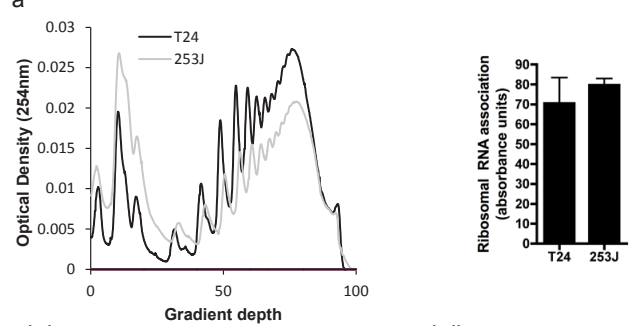

b i
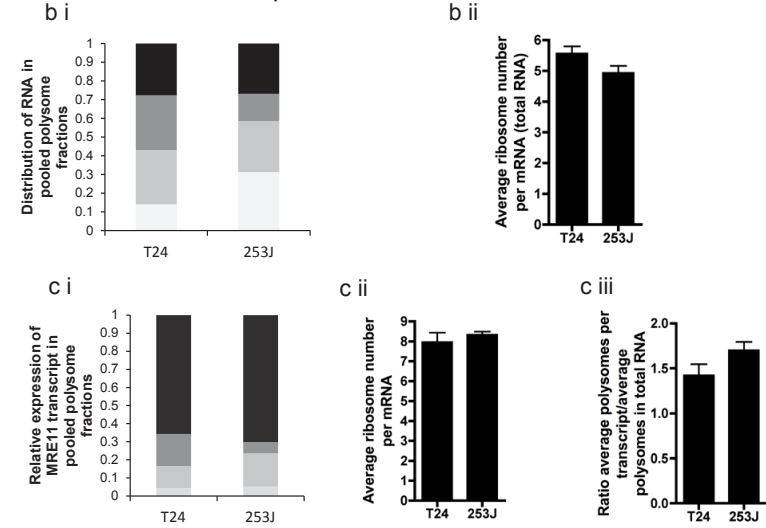

Figure 4: Polysome assay performed on T24 and 253J cells. a) example polysome plot of overall translation, with sum of total RNA for each cell line derived from polysome plot; b)(i) Example of distribution of RNA in fraction pools corresponding to 0-1 (light grey), 2-4 (medium grey), 5-7 (dark grey) and >7 (black) ribosomes. (ii) average ribosome number per mRNA of total RNA, c(i) Example of MRE11 transcript distribution across fraction pools as determined by QPCR (legend as for b(i)), (ii) mean ribosome number per MRE11 mRNA, (iii) rate of translation of MRE11 adjusted for global differences in translation. 
tumours. We therefore assessed whether or not protein expression of MRE11 was influenced at the level of translation initiation using the polysome assay. The T24 cell line has a lower MRE11 protein:RNA ratio (1:1.7) than the $253 \mathrm{~J}$ cell line $(1: 0.5)$ so we hypothesised that translation initiation in T24 cells would be lower than in 253J cells. QPCR was carried out on RNA extracted from fractions separated on a sucrose gradient corresponding to those mRNAs attached to $0-1,2-4,5-7$ or $7+$ ribosomes.

The overall levels of protein synthesis (percentage of ribosomes involved in translation) was similar in both lines (Figure 4a). The distribution of mRNA within the polysome gradient was also similar (Figure 4bi). The average ribosome number per mRNA transcript, determined from these distributions, was slightly lower for 253J cells although this did not reach statistical significance (Figure 4bii). In contrast to our hypothesis, QPCR demonstrated no significant differences in MRE11 translation between the two cell lines, even once adjusted to compensate for differences in global translation by normalisation against average ribosome number per mRNA transcript (Figure $4 \mathrm{c}, \mathrm{p}=0.15$ ). These data suggest that the discrepancy between MRE11 mRNA and protein levels cannot be explained in these two cell lines by differences in translation initiation, nor was there a difference in miR-153 levels (Supplementary Figure 4).

\section{Bladder cancer cell lines have generally stable MRE11, RAD50 and NBS1 mRNA and protein levels}

RNA stability was measured by treatment with $1 \mathrm{ug} / \mathrm{ml}$ Actinomycin D, an inhibitor of transcription, followed by QPCR using SYBR Green. The efficacy of Actinomycin D is reflected in the rapid decrease in c-MYC RNA in all cell lines (Figure 5a). MRE11 and NBS1 were relatively stably expressed in all three lines tested (Supplementary Figure 3); RAD50 was also stable in T24 cells but RAD50 mRNA levels fell by $37.2 \%$ $(p=0.0052)$ and $34.1 \%(p=0.019)$ in $253 \mathrm{~J}$ and RT112 cells,

a

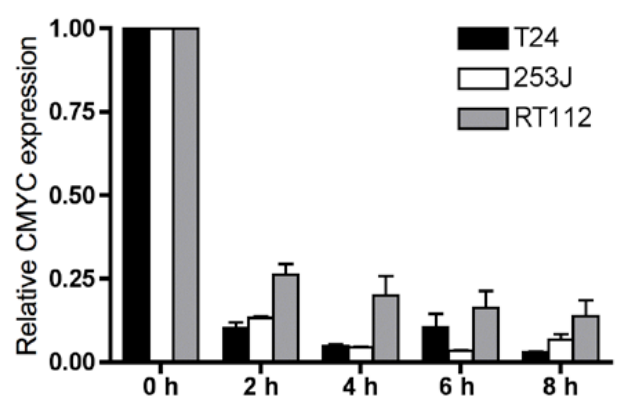

respectively, by 6 hours, with half lives calculated as 229 hours and 2.45 hours. All half-lives were statistically significantly greater than those of c-Myc in individual cell lines (Figure 5b and Supplementary Table 3), and represent a general high level of stability for all three MRN transcripts.

Protein stability was determined by treating cells with $100 \mu \mathrm{g} / \mathrm{ml}$ cycloheximide for up to 30 hours (Figure 6). Cell death prevented study over a longer time period. RAD51 levels fell relatively rapidly, confirming cycloheximide's ability to inhibit further translation. All three proteins were significantly more stable than RAD51, with half-lives of at least 25 hours. All half-lives were statistically significantly greater than those of RAD51 in individual cell lines (Supplementary Table 3). There were no statistically significant differences in degradation of MRE11, RAD50 or NBS1 between cell lines.

\section{DISCUSSION}

The aim of this study was to further investigate our observation that patients with low tumour MRE11 expression do worse following radical radiotherapy than high MRE11 expressors [2]. At the start of this study it was not known whether control of MRE11 expression was at the pre-transcriptional (i.e. mutation of the MRE11 gene or epigenetic silencing of $M R E 11$ ), transcriptional or post-transcriptional level. Post-transcriptional processes involved in control of gene expression include mRNA degradation, translation and protein degradation [16]. Also, as the three proteins act in a complex, MRE11 protein expression may be influenced by NBS1 or RAD50 expression.

To compare mRNA and protein expression, we selected a small tumour area for IHC scoring and removal of tissue cores for mRNA extraction and QPCR RNA quantification. We found that MRE11 protein and RNA expression were discordant, implying that MRE11 expression is subject to post-transcriptional control. Posttranscriptional gene regulation is widespread in the cell and accounts for up to $60 \%$ of protein abundance $[17$, b

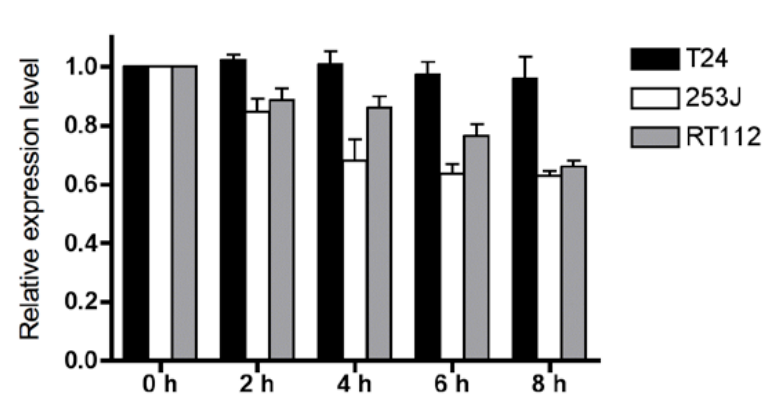

Figure 5: a) c-MYC RNA stability and b) RAD50 RNA stability in T24, 253J and RT112 cells. Relative data expressed relative to time zero $=1.0$ for each transcript. Error bars: SEM of three independent experiments. 
18]. The selection of a small tumour area was necessary, as we previously found that tumour chips from TURBT specimens frequently show heterogeneous MRE11 staining. We found no association between MRE11 protein expression in our single TURBT chip per patient and survival on Kaplan-Meier analysis (data not shown), unlike our previous study, but this reflects our inability to measure tumour heterogeneity in our single chip [19]. This highlights the need to assess all tumour areas immunohistochemically for predictive purposes.

Our clinical findings of discordant MRE11 mRNA/ protein expression were backed up by the cell line data, which additionally showed concordant RAD50 protein/ mRNA and NBS1 protein/mRNA levels, suggesting MRE11 expression is regulated by a post-transcriptional mechanism but not RAD50 or NBS1. Since this study began, Garner and Eastman [20] studied MRN expression in the NCI60 cell line panel, which does not include bladder cancer lines, and found strong correlations for protein expression but not mRNA expression. However, MRE11 RNA and protein expression were more highly correlated than for NBS1 and RAD50, suggesting control of MRE11 at the transcription level. In contrast, our findings suggest that in bladder cancer transcriptional control dominates for RAD50 and NBS1, but MRE11 expression is regulated at the post-transcriptional level. Garner and Eastman concluded that it was the MRN complex formation that determined protein stability. Despite the different underlying mechanisms, our data would concur with this finding. In our study RAD50 and

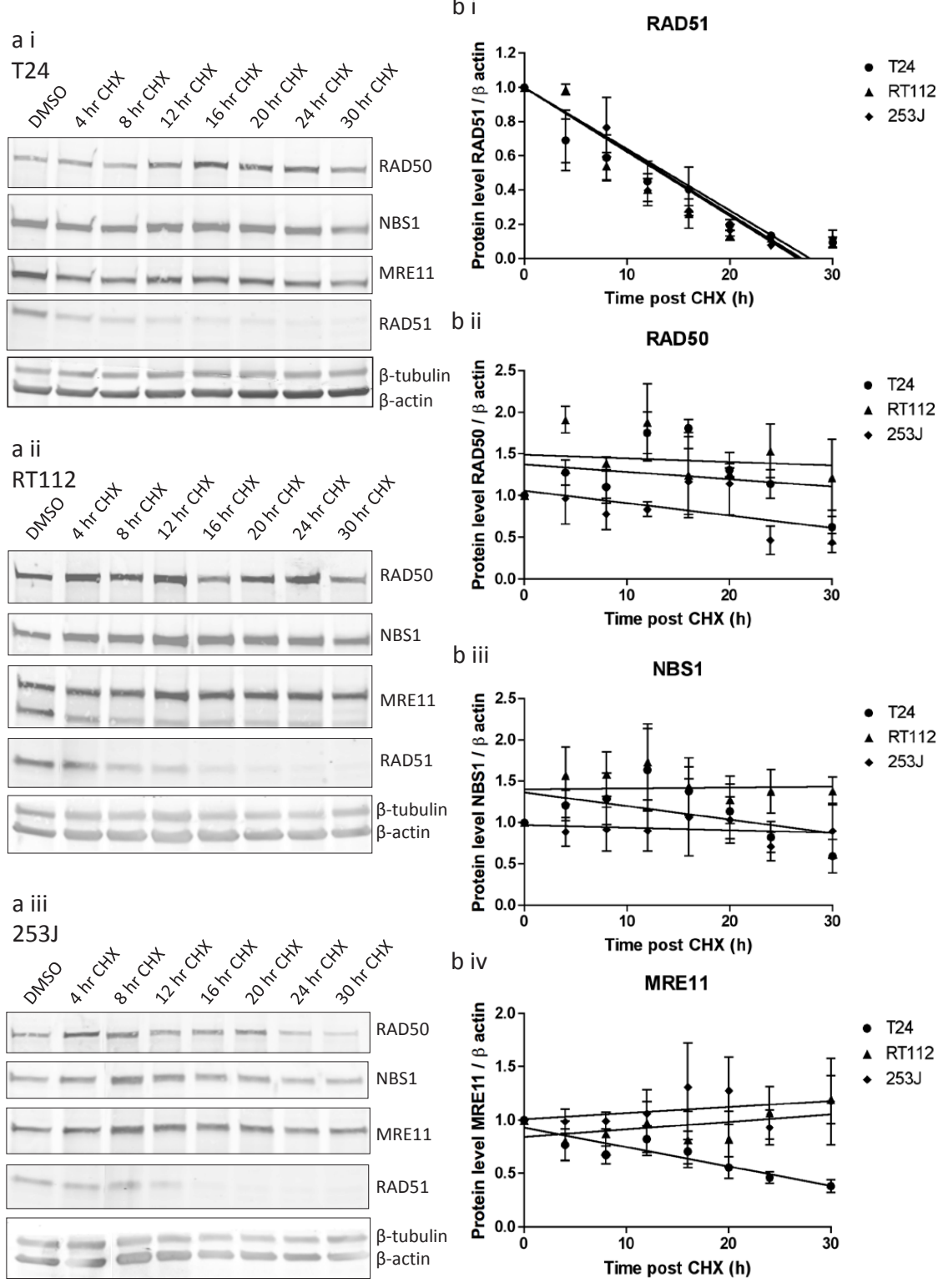

Figure 6: MRE11, RAD50 and NBS1 protein stability in T24, RT112 and 253J cells measured using cycloheximide assay. a) western blots in (i) T24, (ii) RT112, (iii) 253J cells, b) quantification curves for (i) RAD51, (ii) RAD50, (iii) NBS1, (iv) MRE11. Relative data is expressed relative to 1.0 at time zero for each transcript. Error bars: SEM of three independent experiments. 
NBS1 mRNA levels correlated with expression of all three proteins (borderline for NBS1 mRNA and RAD50 protein, $\mathrm{p}=0.058$ ), implying that these two genes are driving the formation of the protein complex, with the MRE11 protein expression then determined by its binding to the complex, with degradation of protein molecules that are not required for complex formation.

MicroRNAs are small, 22-27 nucleotide length, noncoding RNAs sequences which bind to complementary binding sites in the 3'UTR of mRNAs, resulting in mRNA degradation if there is extensive base-pairing complementarity, or inhibition of mRNA translation if complementarity is limited. Either results in posttranscriptional gene silencing [21]. Targetscan identified miR-9 and miR-153 as potential binding partners for the MRE11 3'UTR. In addition, miR-9 and mir-153 have been detected in $94 \%$ and $54 \%$ of urothelial carcinomas, respectively ( $\mathrm{J}$ Catto, personal communication, 30 Oct 2013) with 2.7 and 2.8-fold increases in expression relative to normal urothelial tissue, and we found miR9 expression in $100 \%$ and miR-153 in $76 \%$ of tumours. However, expression was generally low, which may limit their functional impact to a subset of tumours.

Our luciferase assays demonstrated that premiR-153 transfection resulted in reduced expression of the MRE11 3'UTR, which was compatible with our clinical data, where low miR-153 expression was associated with high MRE11 protein expression in clinical samples. It is biologically plausible that miR-153 binding to the MRE11 3'UTR could inhibit MRE11 protein expression, through mRNA degradation or the inhibition of translation initiation.

In mouse fibroblasts, Schwanhausser et al found translation rates to be the most important factor determining protein abundance (approx 55\%), followed by transcription (approx 34\%), with mRNA and protein stability less important [16]. Our polysome assay results suggest that the rate of translation of MRE11 may not be an important determinant of MRE11 protein expression in bladder cancer, although we only studied two cell lines. Our data support findings that mRNA and protein stability are the least important factors determining protein abundance. The actinomycin D assay revealed relatively stable mRNA levels for all three genes across three cell lines, with half lives of at least 2.45 hours compared to a mean half live of 33 minutes for RAD51, and data from our cycloheximide experiments showed that all three proteins were also relatively stable with a minimum half life of 23.5 hours compared to a mean of 12.1 hours for c-Myc (Supplementary Table 3).

Our findings are biologically plausible in terms of the MRN complex, as all three proteins are located in the nucleus and involved in the DNA damage response. For this, the fully-formed proteins are required to move rapidly to sites of damage to form foci, involved in damage recognition and repair, and there is not sufficient time for transcription and/or translation to form new protein molecules [22], so proteins with long half-lives are needed. Interestingly, RT112 cells had a lower MRE11 band, not present in the other two cell lines, which declined more rapidly than the full-length protein, and this needs to be investigated further.

Whilst we have studied a number of posttranscriptional mechanisms of MRE11 expression, we have not ruled out the possibility that transcriptional or pre-transcriptional mechanisms might be involved rarely in individual tumours. Both epigenetic and genetic changes, such as amplification of chromosome $6 \mathrm{p} 22.3$, are known to contribute to the development of bladder cancer [23]. Promoter hypermethylation of MRE11 has not been detected in previous bladder cancer studies, nor have gene mutations such as the A poly(T) MRE11 mutation at the intron 4 splice site, seen in upper urinary tract tumours with microsatellite instability [24]. This -1 to -2 frameshift mutation in a run of 11 thymidine residues results in deletion of exons 5 to 7 of $M R E 11$, and reduced expression of a protein lacking exonuclease activity [25-27]. All our cell lines were screened and none carried this mutation. In the presence of such a mutation, MRE11 expression could drive the expression of the MRN complex, as the least abundant protein. Alternative MRE11 transcripts that do not result in a fully functional protein, but which act in a dominant-negative manner, could be detected by QPCR. However, all our MRE11 primers targeted the two common transcripts 1 and 2, and our antibody, binding amino acids 182 to 582 , detects both protein isoforms.

In conclusion, we have found that, in muscleinvasive bladder tumour samples and a panel of bladder cancer cell lines, MRE11 expression is regulated at the post-transcriptional level, while RAD50 and NBS1 undergo transcriptional control. We have investigated a number of post-transcriptional mechanisms, and found that miRNA-153 expression was inversely correlated with MRE11 expression, although miR-153 was only highly expressed in a few tumours, limiting its clinical applicability. MRE11-NBS1-RAD50 exists in a 2:2:2 complex [8] and it appears that RAD50 and NBS1 transcription determines the amount of MRN complex formed, with MRE11 protein levels adapting in line with complex formation.

Regarding clinically-useful biomarkers, immunohistochemistry seems the most useful test and our results highlight the importance of studying MRE11 at the protein rather than mRNA level.

\section{MATERIALS AND METHODS}

Ethical approval was obtained from Leeds (East) Local Research Ethics Committee (studies 02/060 and 04/ Q1206/62). 


\section{Tumour processing for IHC and RNA extraction}

Eighty-eight tumour blocks from pre-radiotherapy transurethral resection of bladder tumour (TURBT) samples collected from 2002 to 2009 were identified as being suitable for this project. Patients were treated with radical radiotherapy for transitional cell carcinoma of the bladder at the Leeds Cancer Centre, West Yorkshire, UK, as per Choudhury et al [2]. An area of each formalin-fixed paraffin-embedded (FFPE) block was identified based on the matched haematoxylin-and-eosin $(\mathrm{H}+\mathrm{E})$ slide, where more than $70 \%$ of cells were tumour cells and the area appeared homogenous, to ensure that any core taken was representative of what was seen on the $\mathrm{H}+\mathrm{E}$ slide. Four cores of tissue were taken from the identified area using a $0.6 \mathrm{~mm}$ tissue microarray corer (Beecher Instruments Inc). Total RNA was isolated using the HP RNA paraffin kit (Roche Diagnostics Ltd) according to manufacturer's instructions, except that cores were lysed for 3 days, quantified by Nanodrop and $200 \mathrm{ng}$ used in a $20 \mu \mathrm{l}$ Taqman reverse transcription reaction (Applied Biosystems). Whole mount sections were stained for MRE11 and the area scored for percentage positive cells and intensity score as per Choudhury et al [2].

\section{Cell culture}

The bladder cancer cell lines RT112 and 253J were a generous gift from Professor MA Knowles, Leeds Institute of Molecular Medicine. They had been authenticated using by extensive genomic analysis (microsatellite typing, conventional karyotypic analysis, M-FISH and array based copy number analysis). The cell lines 5637, HT1376 and VMCUB-1 were purchased from the German Collection of Microorganisms and Cell Cultures (DSMZ), and J82, T24 and RT4 were purchased from the American Type Culture Collection. RT112, 253J, 5627 and T24 cells were culture in RPMI medium with $10 \%$ fetal calf serum (FCS, Invitrogen). HT1376 and VMCUB-1 cells in DMEM and $10 \%$ FCS, J82 cells in MEM, 1\% non-essential amino acids and 10\% FCS and RT4 cells in McCoy's 5A medium and $10 \%$ FCS. After resuscitation, cell lines were cultured for no more than three months.

\section{Western blot}

Cells were lysed with buffer containing $50 \mathrm{mM}$ Hepes, $100 \mathrm{mM} \mathrm{NaCl}, 10 \mathrm{mM}$ EDTA, $1 \% \mathrm{w} / \mathrm{v}$ Triton, $4 \mathrm{mM}$ sodium pyrophosphate, $2 \mathrm{mM}$ Sodium orthovanadate, 10 $\mathrm{mM}$ sodium fluoride, $50 \mathrm{mM} \beta$-glycerophosphate $\mathrm{pH}$ to 7.5 with $\mathrm{NaOH}$ and $1 \%$ SDS then centrifuged at $14,000 \mathrm{G}$ for 10 minutes to obtain the total cell lysate. The BCA assay (Fisher) was used to determine protein concentration and $50 \mu \mathrm{g}$ of protein was loaded on an $8 \%$ or $4-20 \%$ SDS-
PAGE gel, transferred to a nitrocellulose and probed with antibodies against MRE11 (Abcam, AB214), NBS1 (Novus Biologicals), RAD50 (Cell Signalling, \#3427), RAD51 (Santa Cruz), $\beta$-tubulin (Sigma) and $\beta$-actin (Abcam). Fluorescent secondary anti-mouse 800 and anti-rabbit 680 antibodies (Licor Biosciences) were used at 1:5,000 and visualised and quantified on an Odyssey machine.

\section{Real-time PCR}

For quantification of MRE11 mRNA in tumour cores and the bladder cancer cell line panel, $2 \mu \mathrm{l}$ of reverse transcription product was used in a $20 \mu \mathrm{l}$ QPCR using Hs00271551_m1 Taqman assay with Taqman gene expression master mix. ATP5B, Hs00969569_m1, and SDHA, Hs00188166_m1, were used as endogenous controls (Applied Biosystems) [28, 29]. RNA extracted from FFPE tissue is not of the same quality as RNA extracted from cell lines but valuable QPCR data can be obtained within the limitations involved and by monitoring endogenous control signal [30].

For expression analysis of mRNA in cell lines in subsequent experiments, SYBR green PCR master mix was used with primers for MRE11:F-TGAGGAGGTAC GTCGTTTCA,TCCATCTGGCATAAATGATGA, R-GTGGAAGTTTTCCTGCTCCA;RAD50:FGAGATTTCCCTCCTGGAACC,RACATCACGAAATTGCAGACG;ATP5B:FACCATCAAAGGATTCCAGCA,RGCTTTTGCCACAGCTTCTTC;SDHA:FTGGGAACAAGAGGGCATCTG,RCCACCACTGCATCAAATTCATG;CMYC:F-CAGCTGCTTAGACGCTGGATT,RGTAGAAATACGGCTGCACCGA.

RNA was isolated using the RNAeasy mini kit (Qiagen). Reverse transcription was performed using the High Capacity cDNA Reverse Transcription Kit (Applied Biosystems).

\section{Luciferase assays}

A vector containing MRE11-3'UTR cloned into the SGG_3UTR vector downstream of luc2P was purchased from Switchgear Genomics. Two hundred nanograms of plasmid vector was transfected into 5637 cells seeded at 15,000 cells per well of a 96-well plate 24 hours previously, along with $20 \mathrm{ng}$ Renilla luciferase containing vector and pre-miR (miR-9 pm10022, miR-153 PM10122 and pre-miR ${ }^{\mathrm{TM}}$ miRNA Precursor Molecules negative control\#1 AM17110, Applied Biosystems) to a final concentration of $250 \mathrm{nM}$ using oligofectamine. Forty eight hours later firefly and renilla luciferase activity was detected on a Polstar Omega plate reader using dual-glo luciferase assay reagents (Promega). 


\section{MicroRNA expression}

MicroRNA expression was determined by QPCR using Taqman Universal master mix (Applied Biosystems) and microRNA assays 00583 for miR-9, $001191 \mathrm{miR}$ 153, (Applied Biosystems). RNU44 (assay 1094) and RNU48 (assay 1006) were used as endogenous controls to normalise expression.

\section{Polysome fractionation and analysis}

Polysome fractionation and analysis was performed as previously described in Koritzinsky et al [31]. Briefly, $70 \%$ confluent cells were treated with $0.1 \mathrm{mg} /$ $\mathrm{ml}$ cycloheximide, lysed and the lysate applied to a sucrose gradient. After centrifugation, $1 \mathrm{ml}$ fractions were collected that contained RNA bound to ribosomes with increasing weight and therefore increasing ribosome number. Fractions were pooled into groups containing 0 or 1,2 to 4,5 to 7 and greater than 7 ribosomes, and RNA was isolated and reverse transcribed. The translation efficiency of specific genes was determined by QPCR analysis to detect the relative amount of each transcript in the pooled fraction groups. Average ribosome number per transcript was calculated and normalised against the average ribosome number for total RNA in each cell line, to adjust for differences in overall translation rate in each cell line.

\section{Actinomycin D assay and cycloheximide treatment}

Cells $\left(1.5 \times 10^{6}\right)$ were seeded in $10 \mathrm{~cm}$ plates the day before treatment with actinomycin D (Sigma) at $1 \mu \mathrm{g} / \mathrm{ml}$ and harvested 2, 4, 6, and $8 \mathrm{~h}$ later for RNA extraction as detailed above. Two hundred nanograms of RNA was used in a $20 \mathrm{ul}$ reaction and $2 \mathrm{ul}$ of a 1 in 5 dilution added to a $20 \mu \mathrm{l}$ QPCR SYBR green reaction. A DMSO carrier control was harvested after 8 hours.

Cells $\left(3 \times 10^{6}\right)$ were seeded in $15 \mathrm{~cm}$ plates the day before treatment with Cycloheximide at $100 \mu \mathrm{g} / \mathrm{ml}$ and harvested up to $36 \mathrm{~h}$ later for protein extraction, as detailed above. However, at 36 hours, cycloheximide caused cell death. A DMSO carrier control was plated at $1 \times 10^{6}$ cells to avoid over-confluency and harvested at $36 \mathrm{~h}$.

\section{Statistics}

Spearman rank correlations and Student's T test were carried out using SPSS 14.0 software. Unless otherwise stated, P values represent Student's T test results.

\section{ACKNOWLEDGEMENTS}

We thank Ms Filomena Estevez for immunohistochemistry staining, and Ms Christiana Kartsonaki for her statistical help.

\section{Financial support}

RMM was funded by Cancer Research UK Project Grant C15140/A10441 and CR-UK Travel Grant C41641/ A13249.

MTWT was funded by Yorkshire Cancer Research Project Grant L350.

SJ was funded by a Medical Research Council studentship.

$\mathrm{MK}^{3}$ and BGW were funded from support from the Ontario Ministry of Health and Long Term Care (OMOHLTC), the Terry Fox Research Institute (New Frontiers Research Program (PPG09-020005 and New Investigator Award), the Ontario Institute for Cancer Research, and the Canadian Institute for Health Research (CIHR grant 201592). The views expressed do not necessarily reflect those of the OMOHLTC.

$\mathrm{MK}^{1}$ and AEK were funded by Cancer Research UK Programme Grant C5255/A15935.

\section{Statement of author contributions}

$\mathrm{RMM}$ and $\mathrm{MK}^{1}$ conceived and carried out experiments, analysed data, and generated figures. MTWT and SJJ carried out experiments and analysed data. $\mathrm{MK}^{3}$ and GBW conceived experiments and analysed data. SB identified muscle-invasive tumour in paraffin blocks, and AEK conceived the study, made tumour cores and guided experiments. RMM, $\mathrm{MK}^{1}, \mathrm{SJJ}, \mathrm{MK}^{3}, \mathrm{BGW}$ and $\mathrm{AEK}$ wrote the manuscript, and all authors had final approval of the submitted version.

\section{REFERENCES}

1. Kotwal S, Choudhury A, Johnston C, Paul AB, Whelan $\mathrm{P}$ and Kiltie AE. Similar treatment outcomes for radical cystectomy and radical radiotherapy in invasive bladder cancer treated at a United Kingdom specialist treatment center. International journal of radiation oncology, biology, physics. 2008; 70(2):456-463.

2. Choudhury A, Nelson LD, Teo MT, Chilka S, Bhattarai S, Johnston CF, Elliott F, Lowery J, Taylor CF, Churchman M, Bentley J, Knowles MA, Harnden P, Bristow RG, Bishop DT and Kiltie AE. MRE11 expression is predictive of cause-specific survival following radical radiotherapy for muscle-invasive bladder cancer. Cancer research. 2010; 70(18):7017-7026.

3. Laurberg JR, Brems-Eskildsen AS, Nordentoft I, Fristrup 
N, Schepeler T, Ulhoi BP, Agerbaek M, Hartmann A, Bertz S, Wittlinger M, Fietkau R, Rodel C, Borre M, Jensen JB, Orntoft T and Dyrskjot L. Expression of TIP60 (tatinteractive protein) and MRE11 (meiotic recombination 11 homolog) predict treatment-specific outcome of localised invasive bladder cancer. BJU Int. 2012.

4. Angele S, Treilleux I, Bremond A, Taniere P and Hall J. Altered expression of DNA double-strand break detection and repair proteins in breast carcinomas. Histopathology. 2003; 43(4):347-353.

5. Soderlund K, Stal O, Skoog L, Rutqvist LE, Nordenskjold $\mathrm{B}$ and Askmalm MS. Intact Mre11/Rad50/Nbs1 complex predicts good response to radiotherapy in early breast cancer. International journal of radiation oncology, biology, physics. 2007; 68(1):50-58.

6. Stewart GS, Maser RS, Stankovic T, Bressan DA, Kaplan MI, Jaspers NG, Raams A, Byrd PJ, Petrini JH and Taylor AM. The DNA double-strand break repair gene hMRE11 is mutated in individuals with an ataxia-telangiectasia-like disorder. Cell. 1999; 99(6):577-587.

7. Takemura H, Rao VA, Sordet O, Furuta T, Miao ZH, Meng L, Zhang $\mathrm{H}$ and Pommier Y. Defective Mre11-dependent activation of Chk2 by ataxia telangiectasia mutated in colorectal carcinoma cells in response to replicationdependent DNA double strand breaks. J Biol Chem. 2006; 281(41):30814-30823.

8. Williams GJ, Lees-Miller SP and Tainer JA. Mre11-Rad50Nbs 1 conformations and the control of sensing, signaling, and effector responses at DNA double-strand breaks. DNA Repair (Amst). 2010; 9(12):1299-1306.

9. Park YB, Chae J, Kim YC and Cho Y. Crystal structure of human Mre11: understanding tumorigenic mutations. Structure. 2011; 19(11):1591-1602.

10. Buis J, Stoneham T, Spehalski E and Ferguson DO. Mre11 regulates CtIP-dependent double-strand break repair by interaction with CDK2. Nat Struct Mol Biol. 2012; 19(2):246-252.

11. Zhuang J, Jiang G, Willers $H$ and Xia F. Exonuclease function of human Mre11 promotes deletional nonhomologous end joining. The Journal of biological chemistry. 2009; 284(44):30565-30573.

12. Lamarche BJ, Orazio NI and Weitzman MD. The MRN complex in double-strand break repair and telomere maintenance. FEBS Lett. 2010; 584(17):3682-3695.

13. Garner KM, Pletnev AA and Eastman A. Corrected structure of mirin, a small-molecule inhibitor of the Mre11Rad50-Nbs 1 complex. Nat Chem Biol. 2009; 5(3):129-130; author reply 130 .

14. Dupre A, Boyer-Chatenet L, Sattler RM, Modi AP, Lee JH, Nicolette ML, Kopelovich L, Jasin M, Baer R, Paull TT and Gautier J. A forward chemical genetic screen reveals an inhibitor of the Mre11-Rad50-Nbs1 complex. Nat Chem Biol. 2008; 4(2):119-125.

15. Hui A, How $\mathrm{C}$, Ito $\mathrm{E}$ and Liu FF. Micro-RNAs as diagnostic or prognostic markers in human epithelial malignancies. BMC Cancer. 2011; 11:500.

16. Schwanhausser B, Busse D, Li N, Dittmar G, Schuchhardt J, Wolf J, Chen W and Selbach M. Global quantification of mammalian gene expression control. Nature. 2011; 473(7347):337-342.

17. de Sousa Abreu R, Penalva LO, Marcotte EM and Vogel C. Global signatures of protein and mRNA expression levels. Mol Biosyst. 2009; 5(12):1512-1526.

18. Maier T, Guell M and Serrano L. Correlation of mRNA and protein in complex biological samples. FEBS Lett. 2009; 583(24):3966-3973.

19. Gerlinger M, Rowan AJ, Horswell S, Larkin J, Endesfelder D, Gronroos E, Martinez P, Matthews N, Stewart A, Tarpey P, Varela I, Phillimore B, Begum S, McDonald NQ, Butler $\mathrm{A}$, Jones $\mathrm{D}$, et al. Intratumor heterogeneity and branched evolution revealed by multiregion sequencing. N Engl J Med. 2012; 366(10):883-892.

20. Garner KM and Eastman A. Variations in Mre11/Rad50/ Nbs1 status and DNA damage-induced S-phase arrest in the cell lines of the NCI60 panel. BMC Cancer. 2011; 11:206:201-213.

21. Macfarlane LA and Murphy PR. MicroRNA: Biogenesis, Function and Role in Cancer. Current genomics. 2010; 11(7):537-561.

22. Nelms BE, Maser RS, MacKay JF, Lagally MG and Petrini JH. In situ visualization of DNA double-strand break repair in human fibroblasts. Science. 1998; 280(5363):590-592.

23. Shen H, Morrison CD, Zhang J, Underwood W, 3rd, Yang N, Frangou C, Eng K, Head K, Bollag RJ, Kavuri SK, Rojiani AM, Li Y, Yan L, Hill A, Woloszynska-Read A, Wang J, et al. 6p22.3 amplification as a biomarker and potential therapeutic target of advanced stage bladder cancer. Oncotarget. 2013; 4(11):2124-2134.

24. Mongiat-Artus $\mathrm{P}$, Miquel C, Van der Aa M, Buhard O, Hamelin R, Soliman H, Bangma C, Janin A, Teillac P, van der Kwast $T$ and Praz F. Microsatellite instability and mutation analysis of candidate genes in urothelial cell carcinomas of upper urinary tract. Oncogene. 2006; 25(14):2113-2118.

25. Wen Q, Scorah J, Phear G, Rodgers G, Rodgers S and Meuth M. A mutant allele of MRE11 found in mismatch repair-deficient tumor cells suppresses the cellular response to DNA replication fork stress in a dominant negative manner. Mol Biol Cell. 2008; 19(4):1693-1705.

26. Giannini G, Rinaldi C, Ristori E, Ambrosini MI, Cerignoli F, Viel A, Bidoli E, Berni S, D’Amati G, Scambia G, Frati L, Screpanti I and Gulino A. Mutations of an intronic repeat induce impaired MRE11 expression in primary human cancer with microsatellite instability. Oncogene. 2004; 23(15):2640-2647.

27. Giannini G, Ristori E, Cerignoli F, Rinaldi C, Zani M, Viel A, Ottini L, Crescenzi M, Martinotti S, Bignami M, Frati L, Screpanti I and Gulino A. Human MRE11 is inactivated 
in mismatch repair-deficient cancers. EMBO Rep. 2002; 3(3):248-254.

28. Ohl F, Jung M, Radonic A, Sachs M, Loening SA and Jung $K$. Identification and validation of suitable endogenous reference genes for gene expression studies of human bladder cancer. J Urol. 2006; 175(5):1915-1920.

29. Andersen CL, Jensen JL and Orntoft TF. Normalization of real-time quantitative reverse transcription-PCR data: a model-based variance estimation approach to identify genes suited for normalization, applied to bladder and colon cancer data sets. Cancer Res. 2004; 64(15):5245-5250.

30. Conway C, Mitra A, Jewell R, Randerson-Moor J, Lobo S, Nsengimana J, Edward S, Sanders DS, Cook M, Powell B, Boon A, Elliott F, de Kort F, Knowles MA, Bishop DT and Newton-Bishop J. Gene expression profiling of paraffinembedded primary melanoma using the DASL assay identifies increased osteopontin expression as predictive of reduced relapse-free survival. Clin Cancer Res. 2009; 15(22):6939-6946.

31. Koritzinsky $M$, Seigneuric R, Magagnin MG, van den Beucken T, Lambin P and Wouters BG. The hypoxic proteome is influenced by gene-specific changes in mRNA translation. Radiother Oncol. 2005; 76(2):177-186. 